\title{
Time on the Market: The Impact of Residential Brokerage
}

\begin{abstract}
This paper examines the impact of brokers, brokerage firms and marketing strategy on time on the market (TOM) in the residential housing market. Using a duration model methodology, the study finds duration dependence to be positive, suggesting that the probability of sale increases with TOM. Pricing-related marketing strategies are found to strongly influence TOM, but individual agent and firm characteristics are not statistically significant. These results are consistent with an efficient market within a multiple listing service-no group of agents or firms appears to possess special advantages enabling them to sell homes more quickly than their rivals.
\end{abstract}

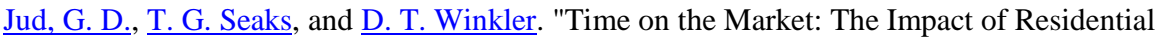
Brokerage," Journal of Real Estate Research, vol. 12, no. 3, 1996, pp. 447-458.

Made available courtesy of American Real Estate Society

\section{Introduction}

Residential housing is not a liquid asset, as anyone who has ever tried to sell a house can attest. Because housing is illiquid, homesellers often employ real estate brokers to assist with a sale. This paper assesses the impacts of brokers, brokerage firms and price-related marketing strategies on housing liquidity.

The degree of housing market illiquidity is most often measured by time on the market (TOM). A number of studies have examined the determinants of TOM. Belkin, Hempel and McLeavey (1976) demonstrate that TOM is a positive function of the difference between listing price and selling price. Miller (1978) reports a positive relationship between list price and TOM. Additional studies by Janssen and Jobson (1980), Kang and Gardner (1989), and Asabere, Huffman and Mehdian (1993) have confirmed that listing price and above-market pricing affect TOM. These studies, however, use regression analysis instead of the more appropriate duration model approach.

Kalra and Chan (1994), Yang and Yavas (1995a), and Haurin (1988) report that TOM is influenced by local and national economic conditions and is subject to strong seasonal effects. Haurin (1988), drawing on search theory developed by Feinberg and Johnson (1977), shows that TOM is positively related to the atypicality of a house, that is, more unusual houses require more time to market.

Haurin also reports that larger brokerage firms sell homes more rapidly than smaller ones. The effect of brokerage firm size on TOM is confirmed by Larsen and Park (1989) and Sirmans, Turnbull and Benjamin (1991); however, Yang and Yavas (1995a) report that the size of the selling firm has no effect. In a separate study, Yang and Yavas (1995b) find that homes listed and sold by the same brokerage firm do not sell more rapidly than others. Their findings do not support the suspicions of some researchers (see Carney,

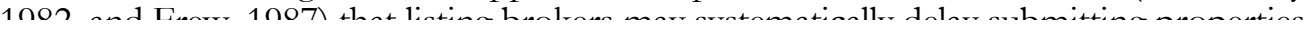

*Bryan School of Business and Economics, Unıversity of North Carolina at Greensboro, Greensboro, North Carolina 27412. 
to their multiple listing service (MLS) that they expect to sell quickly and at low cost. Sirmans, Turnbull and Benjamin (1991) also find no support for this proposition. Yang and Yavas (1995b) report further that commission rates of selling agents do not significantly impact TOM; however, increases in the number of listings (sales) of the listing agent increases (decreases) TOM.

Most brokers try to represent themselves as having special abilities and knowledge that enable them to sell a home more quickly and at a higher price than their rivals. When choosing a real estate agent to sell a home, sellers often are encouraged by broker advertising to select the agent who touts selling a home at a higher price in a shorter period of time. The question in which we are interested is whether the seller's choice of a real estate agent affects housing liquidity, or TOM. From the seller's perspective, the issue is whether there are savings in marketing time to listing with some agents or firms in preference to others. Section two of the paper formulates an analytical model to assess agent performance. Sections three and four present the methodology and sample data, respectively. Section five sets forth empirical estimates of the model, and the final section summarizes findings and discusses the implications of the study.

\section{Real Estate Brokers and Housing Liquidity}

Assume that all houses are sold within an MLS. The market price $(P)$ of the average home is given by:

$$
P=a_{0}+a_{1}^{*} T O M+H^{*} X+A^{*} Z+u_{p},
$$

where TOM is time on the market, $X$ is a vector of housing and neighborhood characteristics, and $Z$ is a vector of factors that affect both price and $T O M$, such as, the degree of overpricing, atypicality, market conditions, and seasonality, and firm and broker characteristics.

We define a home's "expected" market value $(\hat{P})$ to be the value predicted by a hedonic equation, which is estimated by the regression of selling price $(P)$ on the vector $X$ :

$$
\hat{P}=H^{*} X
$$

Substituting equation (2) into equation (1) gives the following:

$$
P^{E}=b_{0}+b_{1}^{*} T O M+B^{*} Z+e_{p},
$$

where, $P^{E}=P-\hat{P}$, or "excess" price.

It is expected that $b_{1}>0$. Increasing TOM is anticipated to raise the probability of finding a buyer willing to pay a higher price. ${ }^{1}$

Likewise, TOM is given by:

$$
T O M=c_{0}+c_{1} * P^{E}+C^{*} Z+u_{t} .
$$

It is expected that $c_{1}>0$.

The reduced form equation of this simultaneous system is found by substituting equation (3) into equation (4), yielding the following:

$$
T O M=\left(c_{0}+c_{1} b_{0}\right) /\left(1-c_{1} b_{1}\right)+\left[\left(c_{1} B+C\right) /\left(1-c_{1} b_{1}\right)\right]^{*} Z+e_{t} .
$$


Equation (5) can be simplified to:

$$
T O M=d_{0}+D^{*} Z+e_{t}
$$

A number of factors included in the vector $Z$ have been identified in previous research. These include the degree of above-market pricing, atypicality, market conditions, and seasonality. Our study introduces characteristics of the listing and selling brokerage firms and the listing and selling agents.

The null hypothesis of the study is that there are no significant differences among firms or agents in the time required to sell brokered homes. ${ }^{2}$ The basic question of the study, therefore, may be formulated as: Are there marketing time savings attributable to the productivity of brokerage firms or agents?

\section{Methodology}

In this study, the dependent variable is a home's time until sale or time on the market (TOM). Many empirical TOM studies have relied on log-linear regression models (Belkin et al., 1976; Miller, 1978; Sirmans et al., 1991). Although it is sometimes possible to use a regression log-linear regression approach, Kiefer (1988) details the numerous transformations of the OLS model required to correct for OLS deficiencies. For example, test statistics will be incorrect because of non-normality of the error term. In addition, because the mean of the error term is non-zero, the intercept estimate must be adjusted. Censoring of data can be accommodated using Tobit-like methods; however, the estimation problem becomes nonlinear in nature.

Duration models have been used more recently in TOM research (Zuehlke, 1987; Yang and Yavas, 1995b). The survival function originates from the distribution function $F(t)$, and is defined by the probability that the random variable TOM will exceed some value defined as $t^{3}$

$$
\begin{aligned}
S(t) & =1-F(t) \\
& =\operatorname{Pr}(T O M \geq t) .
\end{aligned}
$$

The hazard function, which is related to the survival function, is the rate at which home sales are completed after duration $t$ given that they last at least until time $t$. Given the probability density functionf $(\mathrm{t})$ corresponding to $F(t)$, the hazard function is specified as follows:

$$
\lambda(t)=f(t) / S(t)
$$

The choice of duration model depends on the choice of hazard function. In analyses where the hazard rate does not vary over time, i.e., the probability of a sale is the same regardless of when the observation is made, the exponential distribution provides simple and accurate parameter estimates. However, prior studies of TOM indicate the hazard rate is not constant (Zuehlke, 1987; Yang and Yavas, 1995b). Yang and Yavas (1995b) detect negative duration dependence using a Weibull duration model, which corresponds to less chance of a home sale as time progresses. ${ }^{4}$ The Weibull hazard function is flexible, as it assumes a monotonically increasing or decreasing function. ${ }^{5}$ The Weibull hazard function is: 


$$
\lambda(t ; X)=\gamma \alpha t^{\alpha-1}
$$

where $y=\exp (X \beta), \alpha$ is the duration dependence parameter, and $X$ is the vector of regression variables. The exponential hazard function is a special case of the Weibull model occurring when $\alpha=1$.

Heterogeneity occurs if individual observations in a population have different distributions. Although explanatory variables are included in the duration model to control for heterogeneity, they may not provide a complete specification or not be observable variables. In this case, individual observations have differing duration distributions, which renders misleading inferences about duration dependence and included explanatory variables (Kiefer, 1988). In general, heterogeneity leads to a downward bias in duration dependence. Greene (1993) notes that the gamma Weibull model offers corrections for problems associated with heterogeneity of the survival distribution. Using the Weibull duration model with correction for heterogeneity, Zuehlke finds vacant houses exhibit positive duration dependence, suggesting it is more likely that the duration will end as time progresses.

Using the Weibull hazard function, with LTOM $_{l}$ as the natural logarithm of time on the market for home $i$, the operational model is defined as follows:

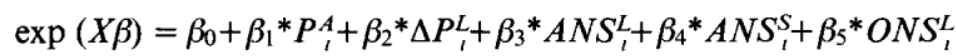

$$
\begin{aligned}
& +\beta_{6}{ }^{*} O N S_{1}^{S}+\beta_{7} F R S_{1}^{L}+\beta_{8}{ }^{*} I_{\imath}+\beta_{9}{ }^{*} A T Y_{\imath}+\beta_{10} * E C O_{\iota},
\end{aligned}
$$

where:

$P_{l}^{A}=$ the degree of above-market pricing, as measured by the difference between the natural logarithm of the list price and the natural logarithm of the predicted price from a hedonic price equation; 6

$\Delta P_{l}^{L}=$ the natural logarithm of the original list price minus the natural logarithm of the final list price;

$A N S_{t}^{L}=$ the natural logarithm of the total number of home sales for the agent listing home $i$;

$A N S_{t}^{S}=$ the natural logarithm of the total number of home sales for the agent selling home $i$;

$O N S_{l}^{L}=$ the natural logarithm of the total number of home sales for the office listing home $i$;

$O N S_{i}^{S}=$ the natural logarithm of the total number of home sales for the office selling home $i$;

$F R S_{\imath}^{L}=$ a dummy variable for franchise affiliation of the office listing home $i$;

$I_{t}=$ a dummy variable for identical listing and selling offices for home sale $i$;

$A T Y_{\imath}=$ the degree of atypicality of home $i$ (see Haurin, 1988);

$E C O_{t}=$ a vector of variables to capture regional economic and seasonal effects when selling home $i$ including the unemployment rate (URATE), the mortgage interest rate $(M R A T E)$, and a dummy variable for the summer months $(S U M M)$.

Including the degree of above-market pricing $\left(P_{l}^{A}\right)$ and change in listing price $\left(\Delta P_{l}^{L}\right)$ variables in equation (7) provides a test of the marketing strategy employed by the listing agent and the homeseller. A number of prior studies have confirmed the importance of 
$P^{A}$. In these studies, above-market pricing contributes to longer TOM (Asabere et al., 1993). However, repricing signals also may affect the home's time on the market. When changing the list price of a home, a new signal may be sent to market participants about the seller's threshold price. If a seller's threshold price is reduced, the home's time on the market should be reduced. The relisting effect $\left(\Delta P_{l}^{L}\right)$ is measured as the difference between the $\log$ of the original list price and the log of the final list price, or the percentage change in the list price.

Other independent variables in the model capture the effects of agent and firm characteristics and expertise. Listing and selling agents may possess special advantages because of numerous factors such as work experience, training and other resources. ${ }^{7}$ Although these factors contribute to agent productivity, the many and varied nature of these variables makes measurement difficult. We focus on the outcome of these measures which is the number of sales consummated for the listing $\left(A N S_{t}^{L}\right)$ and selling agents $\left(A N S_{l}^{S}\right){ }^{8}$ Conventional wisdom suggests that listing agents who have sold many homes help the seller sell quickly. From the selling agent's perspective, a successful selling agent may be one who spots what the buyer wants and persuades the buyer to pay the seller's price. Therefore, an experienced selling agent offering guidance to the buyer might result in faster sales. ${ }^{9}$

Variables representing the number of sales for the selling and listing offices capture differences in organizational efficiencies such as reputation and firm-specific advertising or selling techniques that may enable the selling or listing firm to market the home more rapidly. The existence of statistically significant parameters for listing $\left(O N S_{l}^{L}\right)$ and selling $\left(O N S_{l}^{S}\right)$ firms supports the argument that some firms have special abilities and knowledge that give them a marketing edge. A separate dummy variable for franchise offices $\left(F R S_{t}^{L}\right)$ is included in the model to determine if franchise firms sell homes more quickly than non-franchise firms. One possible explanation is that franchise firms have better informational access and greater advertising than non-franchise firms.

Another issue is the question of whether having the identical listing and selling firm involved in a transaction creates a marketing time advantage. ${ }^{10}$ An independent variable (I) captures whether or not the listing and selling firm are the same for a home sale transaction ( $I=1$ if same, 0 otherwise).

\section{Sample Data}

The model is tested using data from the Greensboro Regional REALTORS Association (Greensboro, North Carolina) for the period starting September 1991 and ending in September 1993. A total of 4,183 housing transactions formed the initial dataset; however, missing data and incorrect codings reduced the size of the sample. The final dataset consists of 2,285 sales. The homes in the sample represent sales by 111 different brokerage firms involving more than 600 individual real estate agents.

Exhibit 1 shows the descriptive statistics for the variables in the model. Applying the antilogarithm to the maximum number of sales, the listing agent and selling agent maximum values are 39 and 72 , respectively. The minimum is one home sale for listing and selling agents.

The mean time on the market is approximately 108 days, suggesting that the average home is sold in a little more than three months. The rather large standard deviation and maximum TOM of 985 days indicates, however, that the mean is not likely indicative of the actual TOM for a particular home. 


\section{Exhibit 1 \\ Descriptive Statistics}

\begin{tabular}{|c|c|c|c|c|}
\hline Variable & Mean & Std Dev. & Minimum & Maximum \\
\hline TOM, & 108.0455 & 109.6955 & 1.0000 & 985.0000 \\
\hline LTOM, & 4.1136 & 1.2565 & 0.0000 & 6.8926 \\
\hline$P_{1}^{A}$ & 0.1882 & 0.1701 & 0.0000 & 1.7220 \\
\hline$\Delta P_{t}^{L}$ & -0.0185 & 0.0431 & -0.4840 & 0.1478 \\
\hline$A N S_{i}^{L}$ & 2.2093 & 0.8463 & 0.0000 & 3.6636 \\
\hline$A N S_{1}^{S}$ & 2.4247 & 0.8249 & 0.0000 & 4.2767 \\
\hline ONS L & 4.7195 & 1.5241 & 0.0000 & 6.2186 \\
\hline ONS S & 5.2215 & 1.5319 & 0.0000 & 6.5917 \\
\hline$F R S_{1}^{L}$ & 0.4219 & 0.4940 & 0.0000 & 1.0000 \\
\hline It & 0.3348 & 0.4720 & 0.0000 & 1.0000 \\
\hline$A T Y_{1}$ & -0.1280 & 0.1690 & -1.4220 & 1.7613 \\
\hline URATE $_{i}$ & 4.8800 & 0.3882 & 3.9000 & 5.4000 \\
\hline MRATE, & 8.2296 & 0.6120 & 7.0400 & 10.0400 \\
\hline SUMM & 0.2788 & 0.4485 & 0.0000 & 1.0000 \\
\hline
\end{tabular}

\section{Results}

The survival function shown in Exhibit 2 illustrates that $50 \%$ of homes are sold within 178 days (about six months) and near $100 \%$ of homes are sold in sixteen months. The shape of the survival function resembles the exponential and Weibull distributions. As Exhibit 3 indicates, the likelihood that a home will sell increases with time until approximately 197 days, reaches a plateau, and then declines at a decreasing rate. This suggests that homesellers initially enjoy increasing prospects for a home sale. However, after some period of time on the market, unsold homes become more difficult to sell. One might interpret these results as increasing visibility and recognition for new home listings, followed by a gradual "stigma" attached to unsold homes.

Exhibit 4 presents the hazard model parameter estimates. The Weibull distribution offers a considerably lower log likelihood than OLS. In addition, the value of $\alpha=1 / \sigma=1.0576$, suggests very slight positive duration dependence. A $95 \%$ confidence interval, $1.0257 \leq \alpha \leq 1.0896$ indicates that Weibull may be preferred to the exponential model.

Duration models are based on the homogeneity of the survival distribution across homes in the sample. If the survival distribution is heterogeneous, parameter estimates will be inconsistent and/or inferences will be based on incorrect standard errors (Gourieroux, Monfort and Trognon, 1984). As $\theta$ deviates from 0 , the greater the effect of heterogeneity. The statistical significance of theta $(\theta)$ from zero for the Weibull model (column 4 in Exhibit 4) indicates the presence of heterogeneity, and requires incorporating heterogeneity into the survival function as shown in the parameter estimates reported in the last column of Exhibit 4. Therefore, our analysis will focus on the Weibull ( $\theta$ heterogeneity) model.

The Weibull model result, incorporating heterogeneity, shows that pricing strategies matter. The statistical significance of the above-market pricing variable $\left(P_{l}^{A}\right)$ suggests that overpricing lengthens a home's time on the market. Conversely, a change in the list price $\left(\Delta P_{l}^{L}\right)$ has the effect of reducing TOM. 


\section{Exhibit 2}

Survival Function

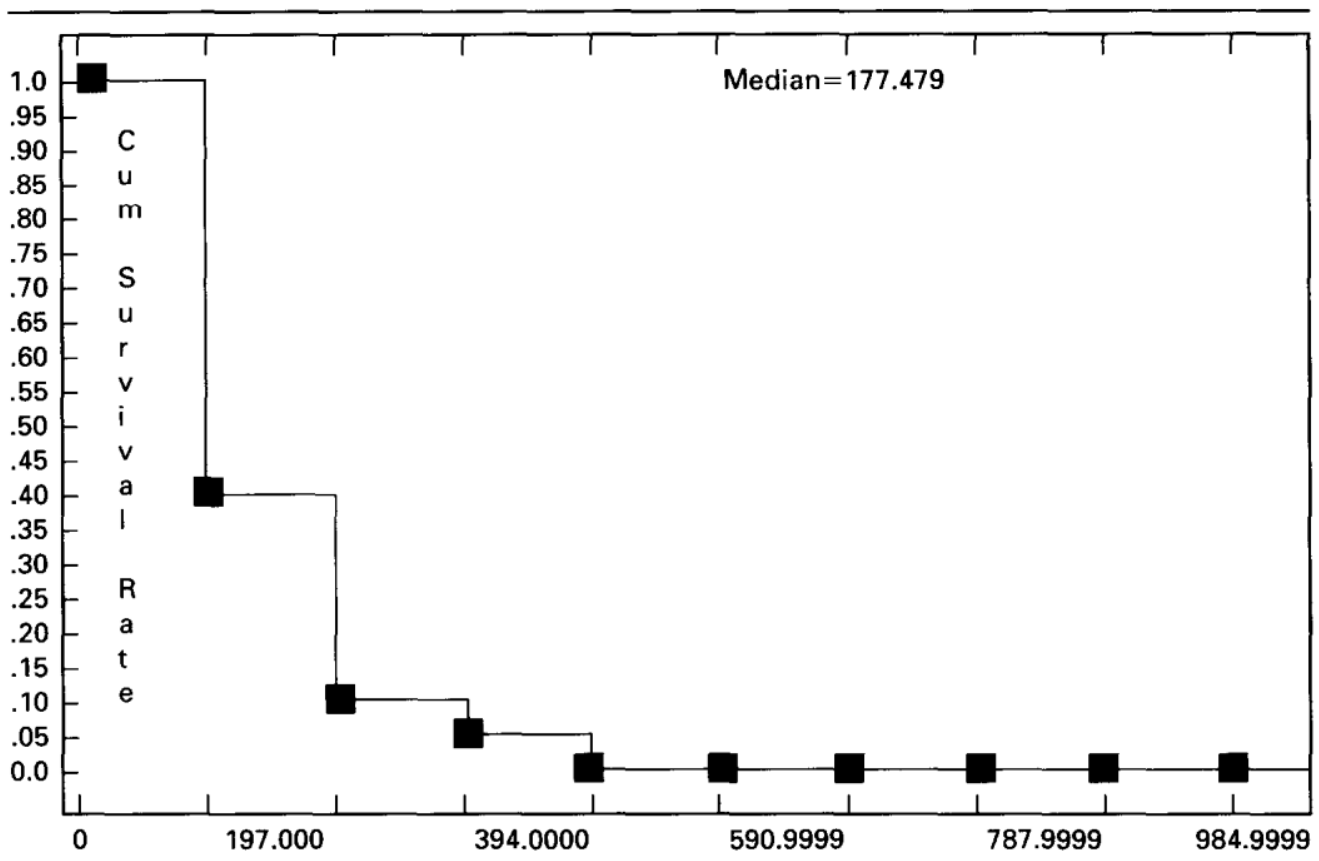

Exhibit 3

Hazard Function

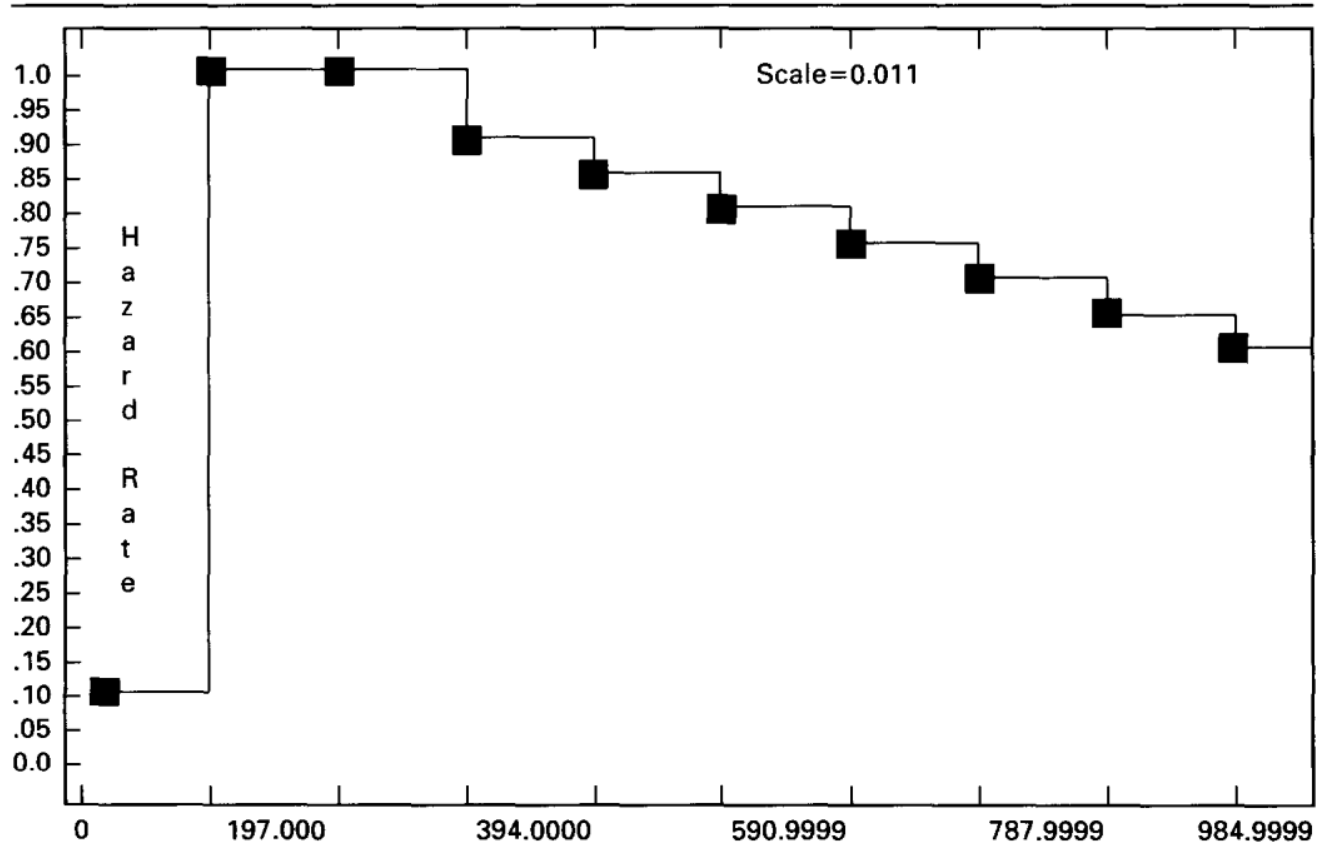


Exhibit 4

Hazard Model Parameter Estimates

\begin{tabular}{|c|c|c|c|c|}
\hline Variable & OLS & Weibull & $\begin{array}{c}\text { Exponential } \\
(\theta \text { Het. })\end{array}$ & $\begin{array}{l}\text { Weibull } \\
(\theta \text { Het.) }\end{array}$ \\
\hline \multirow[t]{2}{*}{ Constant } & 4.6023 & 4.8552 & 4.8269 & 4.7437 \\
\hline & (11.998) & $(16.074)$ & $(13.911)$ & $(14.612)$ \\
\hline \multirow[t]{2}{*}{$P_{1}^{A}$} & 1.6999 & 3.0013 & 2.9685 & 2.8421 \\
\hline & $(4.621)$ & $(9.803)$ & $(8.897)$ & (9.617) \\
\hline \multirow[t]{2}{*}{$\Delta P_{1}^{L}$} & -7.8872 & -3.4360 & -3.7845 & -5.0295 \\
\hline & $(-11.228)$ & $(-7.201)$ & $(-5.963)$ & $(-8.126)$ \\
\hline \multirow[t]{2}{*}{$A N S_{1}^{L}$} & 0.0020 & 0.0487 & 0.0473 & 0.0439 \\
\hline & $(0.061)$ & (1.879) & (1.588) & (1.527) \\
\hline \multirow{2}{*}{$A N S_{i}^{S}$} & -0.0401 & -0.0520 & -0.0501 & -0.0442 \\
\hline & $(-1.286)$ & $(-1.969)$ & $(-1.676)$ & $(-1.604)$ \\
\hline \multirow[t]{2}{*}{ ONS'L } & -0.0090 & -0.0184 & -0.0196 & -0.0240 \\
\hline & $(-0.445)$ & $(-1.137)$ & $(-1.052)$ & $(-1.384)$ \\
\hline \multirow[t]{2}{*}{ ONS } & -0.0059 & 0.0043 & 0.0025 & -0.0038 \\
\hline & $(-0.336)$ & $(0.286)$ & $(0.146)$ & $(-0.245)$ \\
\hline \multirow[t]{2}{*}{$F R S_{\prime}^{L}$} & -0.0667 & 0.0123 & 0.0069 & -0.0098 \\
\hline & $(-1.263)$ & $(0.315)$ & $(0.153)$ & $(-0.219)$ \\
\hline \multirow[t]{2}{*}{ I } & -0.1588 & -0.0255 & -0.0283 & -0.0291 \\
\hline & $(-2.997)$ & $(-0.621)$ & $(-0.603)$ & $(-0.656)$ \\
\hline \multirow[t]{2}{*}{$A T Y}$, & 1.6296 & 2.8685 & 2.8304 & 2.6724 \\
\hline & (4.377) & $(9.180)$ & (8.282) & (8.869) \\
\hline \multirow[t]{2}{*}{ URATE } & 0.2468 & 0.0900 & 0.0960 & 0.1050 \\
\hline & (2.552) & $(1.051)$ & (0.987) & $(1.164)$ \\
\hline \multirow[t]{2}{*}{ MRATE } & -0.2052 & -0.0977 & -0.1004 & -0.1001 \\
\hline & $(-3.169)$ & $(-1.638)$ & $(-1.495)$ & $(-1.654)$ \\
\hline SUMM, & $\begin{array}{l}-0.0498 \\
(-0.835)\end{array}$ & $\begin{array}{l}-0.0605 \\
(-1.303)\end{array}$ & $\begin{array}{l}-0.0613 \\
(-1.142)\end{array}$ & $\begin{array}{l}-0.0666 \\
(-1.303)\end{array}$ \\
\hline \multirow[t]{2}{*}{$\theta$} & - & - & 0.0099 & 0.1619 \\
\hline & - & - & $(0.555)$ & (4.642) \\
\hline \multirow{2}{*}{$\sigma$} & - & 0.9455 & 1.0000 & 0.8517 \\
\hline & - & $(64.842)$ & - & $(40.082)$ \\
\hline$\alpha$ & - & 1.0576 & 1.0000 & 1.1741 \\
\hline$N$ & 2285 & 2285 & 2285 & 2285 \\
\hline Log- $L$ & -3608 & -3449 & -3455 & -3436 \\
\hline Adj. $R^{2}$ & 0.1230 & - & - & - \\
\hline
\end{tabular}

It is interesting to note that neither characteristics of the listing or selling agent had a statistically significant influence on TOM. That is, the number of sales of the listing and selling agents did not have a statistically significant influence on TOM. Similarly, the number of sales listing and selling agent offices had an imperceptible statistical effect on $T O M$, as did whether or not the firm belonged to a franchise. Likewise, TOM does not appear to be reduced if a home is listed and sold by the same brokerage office.

To further examine the impact of the brokerage-related variables, we conducted a joint test of the significance of all the brokerage and agent variables $\left(A N S_{l}^{L}, A N S_{l}^{S}, O N S_{l}^{L}\right.$, $\left.O N S_{t}^{S}, F R S_{\imath}^{L}\right)_{\text {in }}$ the model. Applying a likelihood ratio test to the Weibull model with $O$ heterogeneity (column 4 in Exhibit 4) we calculate a chi-square value (with 5 degrees nf 


\section{Exhibit 5 \\ Integrated Hazard Function}

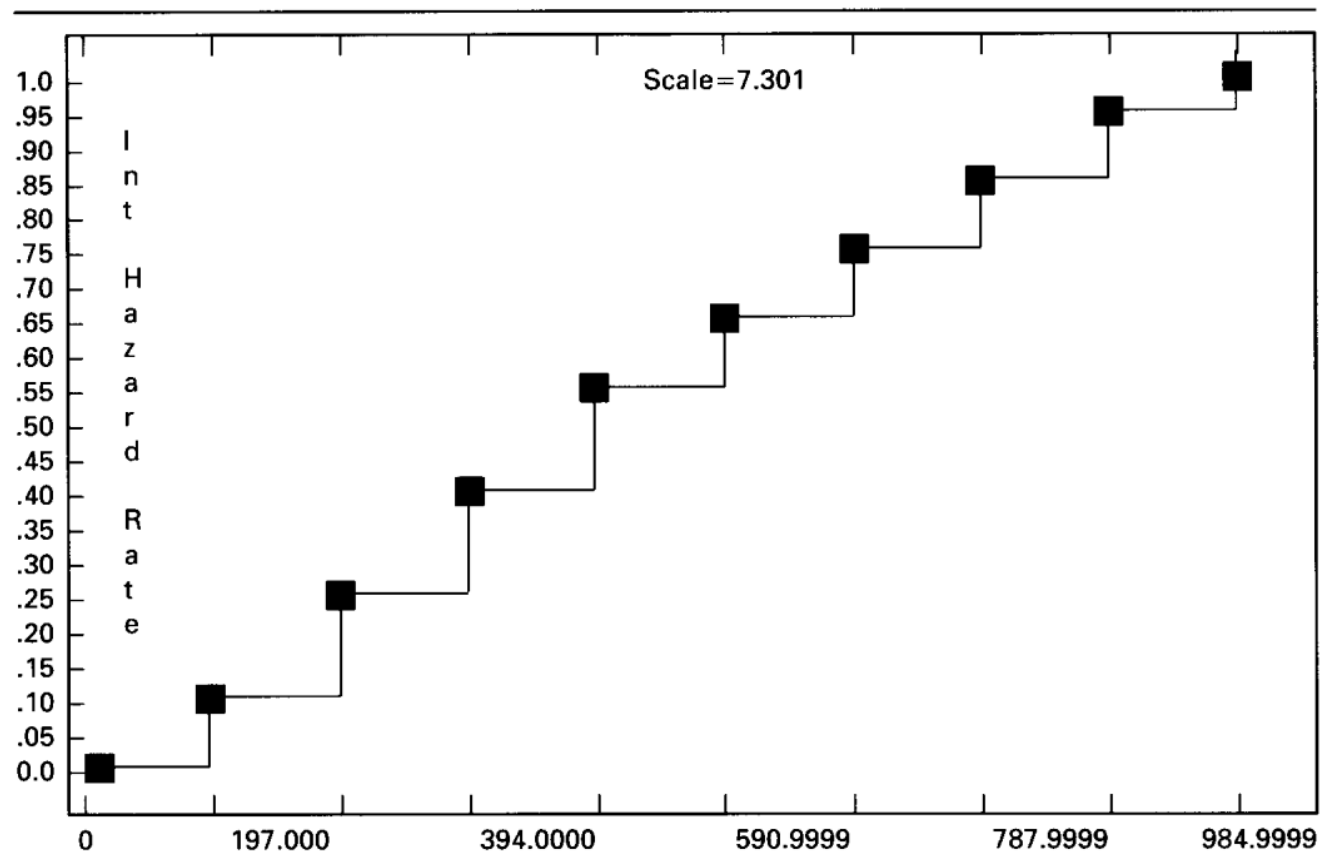

freedom) of 6.99 , which has a probability value of 0.221 . Accordingly, we fail to reject the null hypothesis that the brokerage and agent parameter characteristics vector is zero.

Although the findings of nonsignificance of many broker and brokerage firm characteristics are consistent with those of Yang and Yavas (1995a), they did find that listing the property with a successful listing agent corresponds to decreases in TOM. Our study finds that listing property with a successful agent does not reduce a home's TOM.

In general, the nonsignificance of broker and brokerage firm characteristics is consistent with the notion of an efficient market for home selling. Although successful agents do facilitate the housing market as a whole, the dissemination of information through the multiple listing service creates an efficient market to bring buyers and sellers together for particular home purchases or sales. ${ }^{11}$

As expected, home atypicality is positively related to TOM; homes that are more atypical take longer to sell. This variable has been tested in prior research by Haurin (1988).

\section{Conclusions and Implications}

This paper explores the effect of brokerage firm and agent characteristics on the time it takes to market a home. The study finds no evidence that particular agents or firms are able to market a home faster than others. This finding is consistent with the idea of efficient information flow in the MLS market, where agents and firms do not possess special advantages since information within the MLS is shared. Information 
do not appear to be internally generated either, as we find no evidence that TOM is affected when the listing and selling agents are in the same real estate firm. These results accord with past work reported by Jud and Winkler (1994) showing that there are no differences among brokers in the prices paid for homes in an MLS.

The results indicate that the list price, changes in the list price, and home atypicality are very important determinants of TOM. Higher list prices are associated with higher $T O M$, and reducing the listed price decreases TOM. Home atypicality is directly related to TOM, with more atypical homes having longer average TOM.

\section{Notes}

1 Miller (1978) shows that selling price and TOM are positively related.

2 In terms of the structural equations, a finding that $\mathrm{D}=0$ is consistent with either $B=\mathrm{C}=\mathrm{O}$ or $C=-c_{1} B$. In the first instance, agents and firms have no special influence on price $(B=0)$ and TOM $(\mathrm{C}=0)$. In the second case, the lower TOM resulting from a shift in equation (4) is offset by the higher price caused by a shift in equation (3). In this second case, the implication is that while some agents or firms produce a higher price, there is no influence on TOM. Because our model is not able to identify the structural equations, we cannot distinguish the two alternatives. Thus, our results test only TOM effects. Nevertheless, TOM effects are important. And a recent study of price effects by Jud and Winkler (1994) finds no consistent price effects related to agents and firms, which suggests that the second case is not a relevant alternative.

3 Bandopadhyaya (1994) provides a very clear explanation of duration models within the context of the time that firms spend in Chapter 11 bankruptcy.

4 As new buyers continually enter the pool of homebuyers where homes prices and characteristics are disseminated through the MLS database, it seems reasonable to expect duration to be constant or perhaps slightly positive as agents should be more aware of older listings and therefore, steer potential homebuyers to older listings. On the other hand, if old listings have a "stigma" attached to them, this might explain the finding of negative duration dependence.

5 In addition to the Weibull hazard function, hazards for log-normal and log-logistic distributions first increase and then decrease. Researchers often compute the log likelihood function and plot the survival, hazard, and integrated hazard functions to determine the most appropriate duration model.

6 The hedonic price equation used in this study is the same as that reported in the appendix to Jud and Winkler (1994).

7 For analysis of the determinants of REALTOR productivity and earnings, see Crellin, Frew and Jud (1988) and Glower and Hendershott (1988).

8 Given the number of agents in the study, the use of dummy variables for individual agents is not feasible. The number of dummy variables is too large, and collinearity with the structural variables for the firm exists.

9 One might suspect the possibility of a selectivity bias in the analysis because buyers and sellers are not randomly assigned to real estate firms, but actively pick their brokers. If brokers are chosen by buyers and sellers, then TOM differentials could potentially result from the differences among buyers and sellers, not from differences in broker productivity. Were this to be the case, one would expect to find that house prices vary among different groups of homebuyers. This question has been examined recently by Turnbull and Sirmans (1993). Using MLS data from Baton Rouge, Louisiana, they report no significant differences in housing prices across various groups of buyers. The results of Turnbull and Sirmans (1993) suggest that whatever TOM differentials prevail in the market, they are not associated with identifiable characteristics of homebuyers and sellers.

10 For discussion and evidence of the perceptions of consumers and agents involved in this kind of transaction, see Ball and Nourse (1988). An excellent discussion of the legal issues in this type of 
relationship can be found in Marsh and Zumpano (1988). In our sample of MLS sales in Greensboro, North Carolina, the listing and selling firms were the same in $33 \%$ of the transactions.

11 An analogous argument occurs in the stock brokerage industry. Individual successful stock brokers help make the entire market efficient, but they do not get sellers a higher price or sell a stock sooner.

\section{References}

Asabere, P. K., F. E. Huffman and S. Mehdian, Mispricing and Optimal Time on the Market, Journal of Real Estate Research, 1993, 8:1, 149-56.

Ball, J. N. and H. 0. Nourse, Testing the Conventional Representation Model for Residential Real Estate Brokerage, Journal of Real Estate Research, 1988, 3:2, 119-32.

Bandopadhyaya, A., An Estimation of the Hazard Rate of Firms Under Chapter 11 Protection, Review of Economics and Statistics, 1994, 76:2, 346-50.

Belkin, J., D. J. Hempel and D. W. McLeavy, An Empirical Study of Time on Market Using Multidimensional Segmentation of Housing Markets, AREUEA Journal, 1976, 4:1, 57-75.

Carney, M., Costs and Pricing of Home Brokerage Services, AREUEA Journal, 1982, 10:3, 331-54.

Crellin, G.E., J. R. Frew and G. D. Jud, The Earnings of REALTORS: Some Empirical Evidence, Journal of Real Estate Research, 1988, 3:2, 69-78.

Dasso, J. and A. A. Ring, Real Estate: Principles and Practices, Englewood Cliffs, N.J.: Prentice Hall, 1989.

Feinberg, R. and W Johnson, The Superiority of Sequential Search: A Calculation, Southern Economic Journal, 1977, 43:4, 1594-98.

Frew, J. R., Multiple Listing Service Participation in the Real Estate Brokerage Industry: Cooperation or Competition? Journal of Urban Economics, 1987, 21:3, 272-86.

Glower, M. and P. H. Hendershott, The Determinants of REALTOR Income, Journal of Real Estate Research, 1988, 3:2, 53-68.

Gourieroux, C., A. Monfort and A. Trognon, Pseudo Maximum Likelihood Methods: Theory, Econometrica, 1984, 52:3, 681-700.

Greene, W. H., Econometric Analysis, New York: Macmillan, second edition 1993.

Haurin, D., The Duration of Marketing Time of Residential Housing, AREUEA Journal, 1988, 16:4, 396-410.

Horowitz, J. L., The Role of the List Price in Housing Markets: Theory and an Econometric Model, Journal of Applied Econometrics, 1992, 7:2, 115-29.

Janssen, C. T. L. and J. D. Jobson, On the Choice of Realtor, Decision Sciences, 1980, 11, 299-311.

Jud, G. D. and D. T. Winkler, What Do Real Estate Brokers Do: An Examination of Excess Returns in the Housing Market, Journal of Housing Economics, 1994, 3, 283-95.

Kalra, R. and K. C. Chan, Censored Sample Bias, Macroeconomic Factors, and Time on Market of Residential Housing, Journal of Real Estate Research, 1994, 9:2, 253-62.

Kang, H. B. and M. J. Gardner, Selling Price and Marketing Time in the Residential Real Estate Market, Journal of Real Estate Research, 1989, 4:1, 21-35.

Kiefer, N. M., Economic Duration Data and Hazard Functions, Journal of Economic Literature, 1988, 26:2, 646-79.

Larsen, J. E. and W. J. Park, Non-Uniform Percentage Brokerage Commissions and Real Estate Market Performance, AREUEA Journal, 1989, 17:4, 422-38.

Marsh, G. and L. Zumpano, Agency Theory and the Changing Role of the Real Estate Broker: Conflicts and Possible Solutions, Journal of Real Estate Research, 1988, 3:2, 151-64.

Miller, N. G., Time on the Market and Selling Price, AREUEA Journal, 1978, 6:2, 164-74. 
Sirmans, C. F., G. K. Turnbull and J. D. Benjamin, The Markets for Housing and Real Estate Broker Services, Journal of Housing Economics, 1991, 1:3, 207-17.

Turnbull, G. K. and C. F. Sirmans, Information, Search, and House Prices, Regional Science and Urban Economics, 1993, 23:4, 545-57.

Yang, S. X. and A. Yavas, The Strategic Role of Listing Price in Marketing Real Estate: Theory and Evidence, Journal of the American Real Estate and Urban Economics Association, 1995a, 23:3, 347-68.

__ Bigger is Not Better: Brokerage and Time on the Market, Journal of Real Estate Research, 1995b, 10:1, 23-33.

Zuehlke, T. W, Duration Dependence in the Housing Market, Review of Economics and Statistics, 1987, 69:4, 701-04.

We are grateful for helpful discussions on duration models with Arindam Bandopadhyaya and for guidance on LIMDEP from Bill Greene. LIMDEP version 7.0 was used for all computations. We bear all responsibility for errors. 